\title{
Conflict in Egypt as Depicted in Asian Cartoons
}

\author{
Sara S. Elmaghraby \\ Cairo University, Cairo, Egypt
}

\begin{abstract}
Egypt witnessed great changes between 2011 and 2014 and cartoonists in Asia covered with interest in these changes. This study is a analysis of a number of cartoons drawn from Asian cartoonists on Egypt at that period and seeks at answering some research questions which are the topics covered in Asian cartoons about conflict in Egypt, the symbols used to present the actors in the analyzed cartoons, the humor techniques applied and the visual analogy applied in analyzed cartoons.
\end{abstract}

Keywords: caricature, cartoons, image, Egypt, Asian cartoonists, conflict

\section{Introduction}

Between 2011 and 2014, Egypt witnessed dramatic changes in the political arena. After the 30 years' rule of M. Hosni Mubarak, the 25th of January revolution oust Mubarak declaring the rule of General M. Hussein Tantawy leader of the army and the council of the armed forces.

In 30th of June 2013, the people elected M. Morsi - a member of the Muslim Brotherhood - as president but was a year after oust by General Abdel Fatah ElSisi leader of the army who then was elected as president of Egypt in 2014.

Media, all around the world, followed closely all changes in Egypt and every conflict between different political actors. Researchers in the field of media studies focused heavily on US and European coverage of these conflicts. But only little studies focused on Asian media. Media studies were mainly concerned with coverage of text, content, frames, and discourses of the conflict while cartoons were absent to a great extent. Therefore, this study will focus on the coverage of Asian media especially cartoon of Egypt and its political arena.

\section{Goals of the Study}

This study aims at answering following questions:

RQ1: What are the topics covered in Asian cartoons about conflict in Egypt?

RQ2: What are the symbols used to present the actors in the analyzed cartoons?

RQ3: How are humor techniques applied in analyzed cartoons?

RQ4: To what extent is visual analogy applied in analyzed cartoons?

\section{Methodology}

This study is a qualitative content analysis that is conducted on a sample of 28 cartoons from five Asian countries and seven cartoonists selected from 2011-2014 and collected from the online cartoons directory and archive from www.politicalcartoons.com.

Sara S. Elmaghraby, teaching assistant, Ph.D. student, Journalism Department, Faculty of Mass Communication, Cairo University. 


\section{Literature Review}

Lots of studies in the field of media focused lately on what Egypt has witnessed from political change. Elmaghraby and Abuelela (2014) for example examined how Asharq Alawsat, the New York Times, and Jerusalem Post framed the political change in Egypt from 3rd to 10th of July 2013 and how different the newspapers framed the conflict and the change in Egypt according to their stances and the country they were published from. El Maghraby (2013) conducted a semiological analysis on US cartoons that covered Egypt from February 2011 till February 2013. Pennington (2012) also conducted a study on the coverage of New York Times to the Egyptian revolution. Guzman (2012) studied the coverage of CNN and Fox News of Mubarak during the Egyptian revolution. El Maghraby (2013) compared the coverage of the 30th of June 2014 demonstrations in Egyptian cartoons published in different Egyptian newspapers. Osman and Abdel Samei (2012) compared the coverage of different Egyptian newspaper to the 2011 revolution in Egypt.

\section{Sample of the Study}

As shown in Table 1, this study analyses a total of 28 cartoons drawn by cartoonists from Russia, Israel, India, Iran and China, and the cartoonists Tunin, Zudin, Cohen, Bones, Paresh, Kowsar, and Lujioe.

Table 1

List of Cartoonists

\begin{tabular}{llc}
\hline Country & Cartoonist & No. of analyzed cartoons \\
\hline \multirow{2}{*}{ Russia } & Sergei Tunin & 11 \\
& Alexander Zudin & 1 \\
Israel & Shlomo Cohen & 3 \\
India & Dry Bones & 2 \\
Iran & Paresh & 7 \\
China & Nik Kowsar & 1 \\
Total & Lujioe & 3 \\
\hline
\end{tabular}

\section{Findings}

\section{RQ1: What Are the Topics Covered in the Analyzed Cartoons?}

Table 2 shows that cartoonists in Asia were covering in their cartoons all the important events that Egypt went through for example the 25th of January revolution in 2011, 30th of June 2012 and the elections of M. Morsi the Muslim Brotherhood member as a president of Egypt and his oust in July 2013 by General Abdel Fatah ElSisi. This shows how related the cartoons are with the conflicts in Egypt and all the political changes that Egypt is witnessing and that these cartoons are related closely to the events that occur in Egypt. I claim that Asian cartoons were not only a form of expressing opinion about what is happening in Egypt but it serves as a main source of information and news about Egypt to the Asian reader.

The main topics in the analyzed cartoons: I classified the topics that were published in Asian cartoons chronologically and summed them up in years. I discovered that there were three main themes or topics apparent in the Asian cartoons on Egypt and some sub-themes or topics. The main topics are: In 2011: Conflict between Mubarak and the people (in 13 cartoons), in 2012: Conflict between Mursi and the People (in 11 cartoons), In 2013: Conflict between Mursi and the Military (in 4 cartoons). In the following lines, I will write in details all the sub-themes or topics in these cartoons. 
Table 2

Published Cartoons on Egypt

\begin{tabular}{lllll}
\hline & 2011 & 2012 & 2013 & 2014 \\
\hline January & 2 & & & 1 \\
February & 9 & & & \\
March & & & & \\
April & & 2 & & \\
May & & 1 & \\
June & & 3 & & \\
July & 1 & 1 & & \\
August & & & & \\
September & & & & \\
October & & & & \\
November & & & & \\
December & & & & \\
\hline
\end{tabular}

(1) In 2011: Conflict between Mubarak and the people:

Asian cartoonists drew most of their cartoons on Egypt in 2011 if compared to 2012 and 2013, because that was the year of the Arab Spring in the Arab World in Tunisia, Egypt, Yemen, Syria, and Libya. In 2011, the focus of all cartoonists around the world shifted to the Arab countries. The main topic that was covered by cartoonists at that time was the 25th of January revolution and the conflict that was between Mubarak and the people. Two cartoons covered Mubarak's last speech to the people before resigning and how he tried to clarify his point of view and beg the people to stay in charge. One cartoon depicted how Mubarak's regime has suppressed the protesters in Tahrir Square and how the police tortured one of the protesters who was against Mubarak. Two cartoons were about the oust of Mubarak and how he resigned after the demonstrations. Five cartoons covered the success of the 25th of January revolution and how the will of the people succeeded in forcing Mubarak to resign. In three other cartoons, the US-Egyptian relations were depicted showing how Egypt's foreign policy will change after the revolution heading East and how the US president Barack Obama was supporting Mubarak.

(2) In 2012: Conflict between Mursi and the people:

The year 2012 witnessed the elections in Egypt after 30 years of Mubarak's rule. Egyptians elected a member of the Muslim Brother hood M. Mursi who ran the election race against the former prime minister in Mubarak's regime A. Shafik. Two cartoons depicted the election in Egypt and the race between different candidates for the first time in Egypt. Five cartoons showed Mursi's rule of Egypt. In four cartoons, the conflict between military and president was depicted.

(3) In 2013: Conflict between Mursi and the military:

The military with its head Abdel Fatah ElSisi oust Mursi who was at that time the first elected president this was depicted in two of the cartoons. One cartoon showed the rule of the military led government and another showed massacre of Rabaa in which several of the supporters of the Muslim Brotherhood were killed.

\section{RQ2: What Are the Symbols Used to Present Actors in Analyzed Cartoons?}

The people were the main actors in the analyzed cartoons. In 11 cartoons, Egyptians were depicted sometimes as weak and tortured by the old regime, the police, or the military (see cartoon 1 in Figure 1) and 
other times as strong and victorious especially in relation to the revolution and the elections (see cartoon 2 in Figure 2).

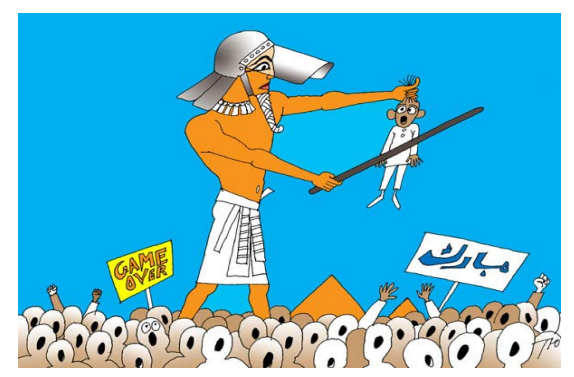

Figure 1. Cartoon 1: Alexander Zudin.

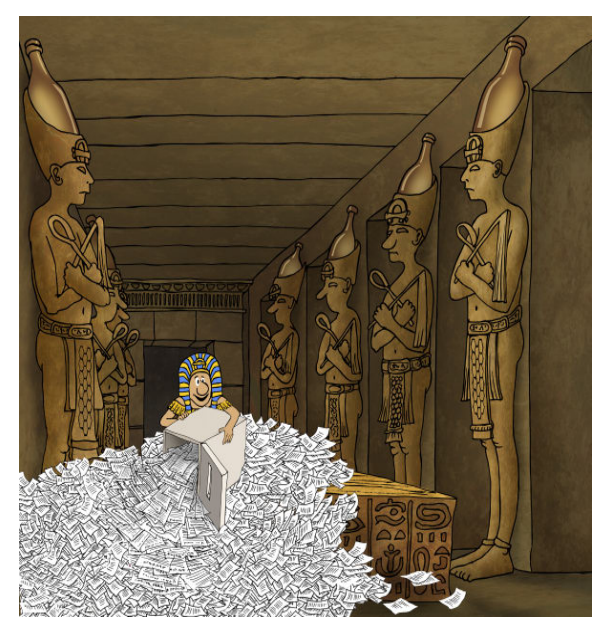

Figure 2. Cartoon 2: Sergei Tunin 29-1-2011.

The second actor that was drawn by the Asian cartoonists was the former president M. Mursi (in eight cartoons) who was sometimes depicted as weak and overwhelmed with problems and obliged to carry heavy weight that he is unable to lift (see cartoon 3 in Figure 3) and strong and pharaonic in other cartoons (see cartoon 4 in Figure 4 ) for example symbolizes Mursi as a Pharaoh and a tyrant who is carried by the Egyptians who are in form of slaves.

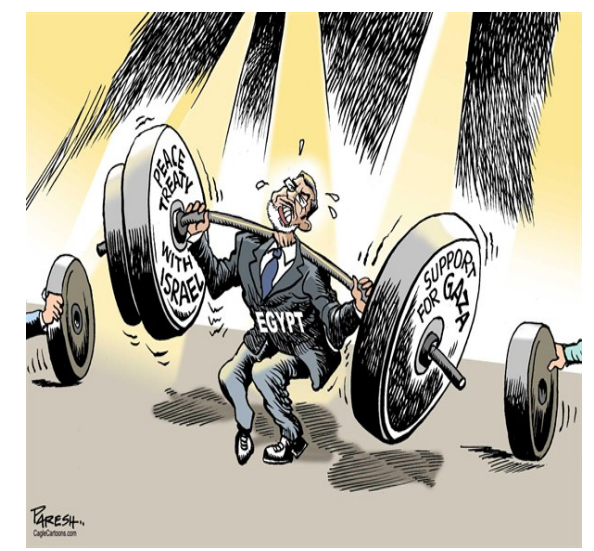

Figure 3. Cartoon 3: Paresh 18-11-2012. 


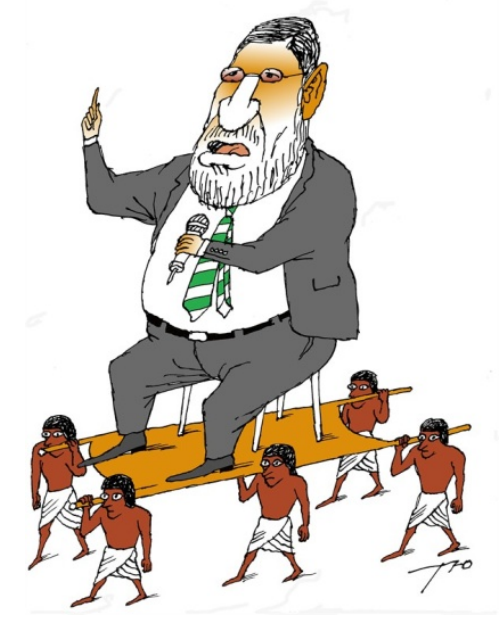

Figure 4. Cartoon 4: Sergei Tunin 25-11-2012.

The former president M. Hosni Mubarak came in third place in the actors present in the analyzed cartoons (in five cartoons). He is always depicted as a tyrant who uses his powers such as the police and his force to oppress his opponents. In cartoon 5 from Figure 5, for example, he is symbolized as sphinx while his head wears the helmet of the police to show that he always uses force and oppression to rule the country.

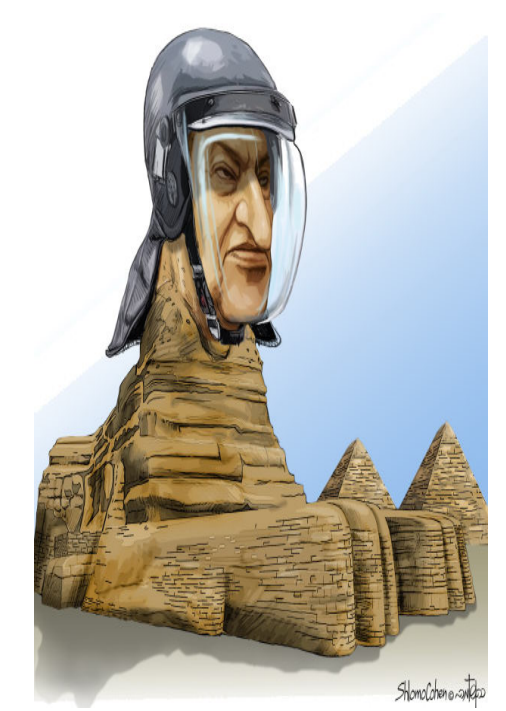

Figure 5. Cartoon 5: Sholomo Cohen 9-2-2011.

In five cartoons, Egypt is depicted. Cartoon 6 in Figure 6 shows how Egypt is begging for money from the Americans and the Arabs and how both are thinking it over whether to give the money or not. This cartoon symbolizes the economic difficulties that Egypt was going through after the oust of Mubarak and the 25th of January revolution and how it seeks support from other countries.

General M. Hussien Tantawy: In cartoon 7 from Figure 7, the Indian cartoonist Paresh draws General of the Army M. Hussein Tantawy as the owner of the power cake in Egypt and how is shocked from the Islamists and M. Morsi to share this cake with him. He is drawn as the one who has all the power in his hands and who wants no one to take the cake from him as an indication that he does not want to transmit the power to the elected president and wants to stay in charge of the country. 


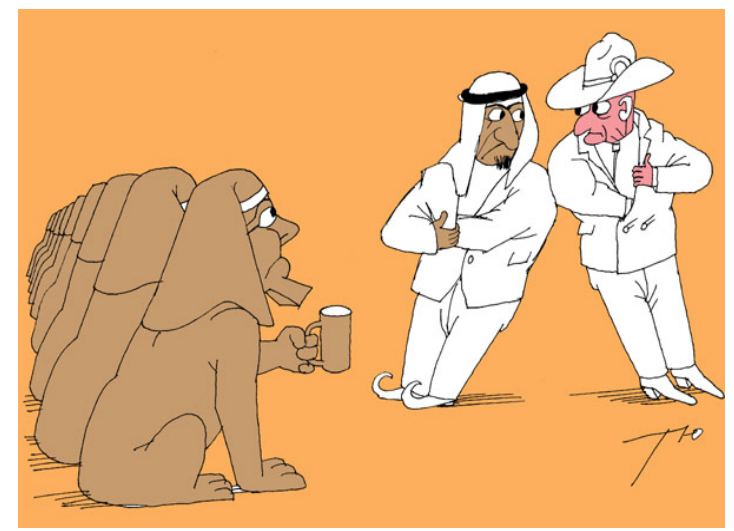

Figure 6. Cartoon 6: Sergei Tunin 11-2-2011.

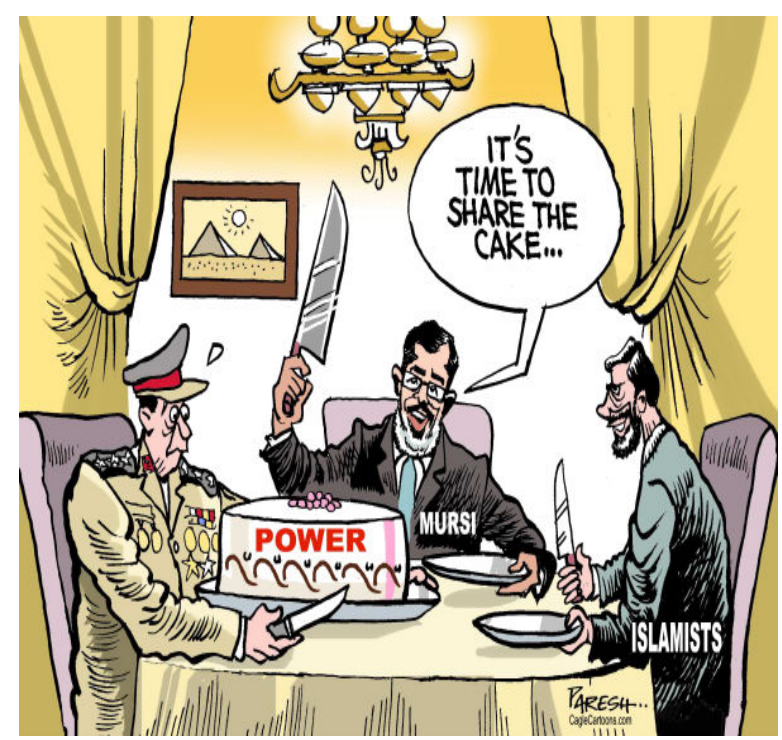

Figure 7. Cartoon 7: Paresh 28-8-2012.

\section{RQ3: How Are Humor Techniques Applied in Analyzed Cartoons?}

To answer this research question, it is to notice that I mean by visual humor in this study three major elements as shown in Figure 8: visual distortion, opposition, and analogy.

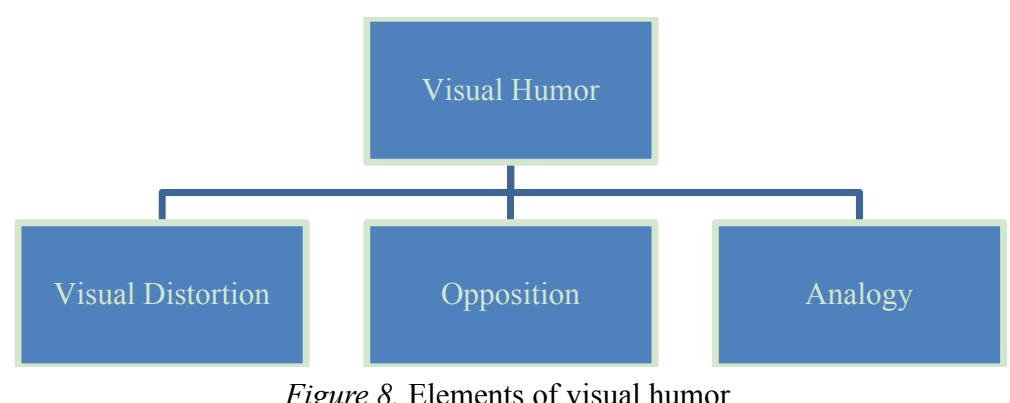

Cartoon 8 in Figure 9 is a good example for the visual distortion as it shows the Libyan former dictator AlGhaddafi distorted as a piece of burger that is put between the bread of Egypt and Tunisia with cheese and ketchup. This cartoon shows us the effect of the revolutions in Egypt and Tunisia on Libya and its president at that time. 


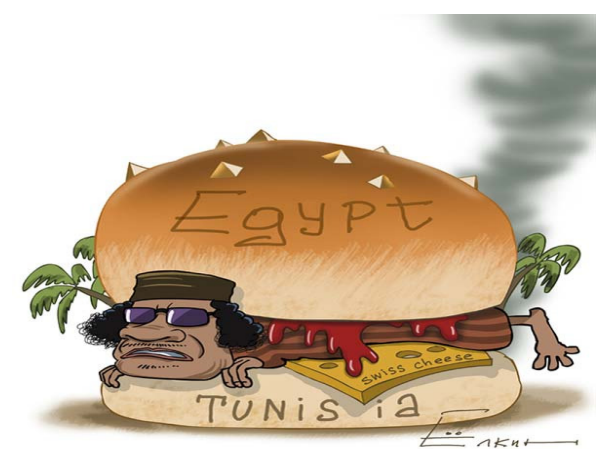

Figure 9. Cartoon 8: Elkin 21-2-2012.

The opposition is very clear in cartoon 9 from Figure 10 of the Russian Sergei Tunin in which the Egyptian people are drawn in two groups opposing each other every group protesting in one side of the pyramid with and against president Mubarak at the time of the Egyptian revolution. This cartoon shows how polarized the Egyptian society was at that time and how divided people were.

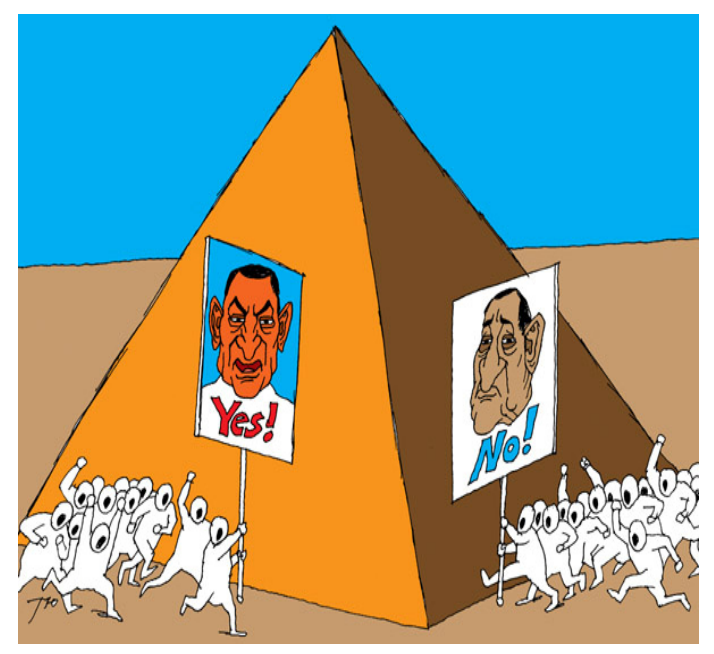

Figure 10. Cartoon 9: Sergei Tunin 2-2-2011.

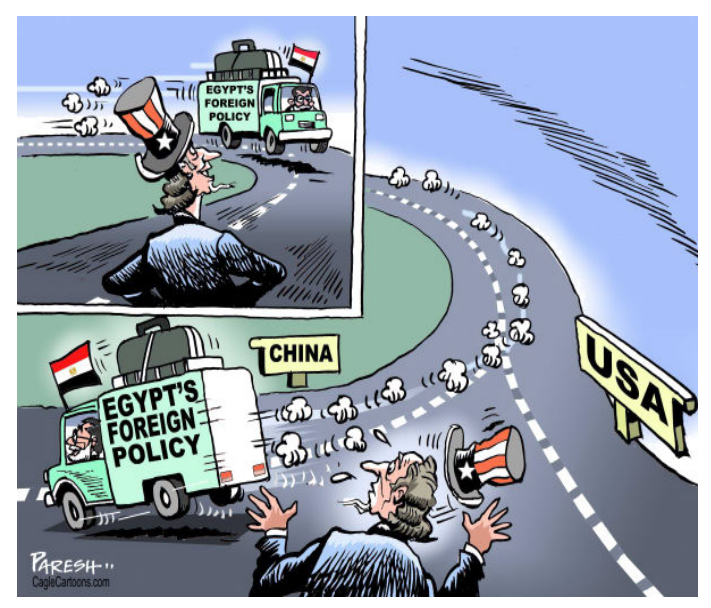

Figure 11. Cartoon 10: Paresh 3-9-2012.

As an example of the analogy, the Indian cartoon (cartoon 10 from Figure 11) shows how the Egyptian foreign policy changed from the US position to the Chinese position and how the revolution of Egypt has made 
Egypt look for replacements to its relations with the United States.

Verbal humor: It is obvious that Dry Bones the Israeli cartoonists has used verbal humor especially in cartoon 11 from Figure 12 that says: "The presidential election in Egypt will offer the voters a choicebetween the two forces that the Egyptian spring revolutionaries opposed, one candidate is from the Muslim brotherhood and the other is from the army".

\section{Drey Bomes}

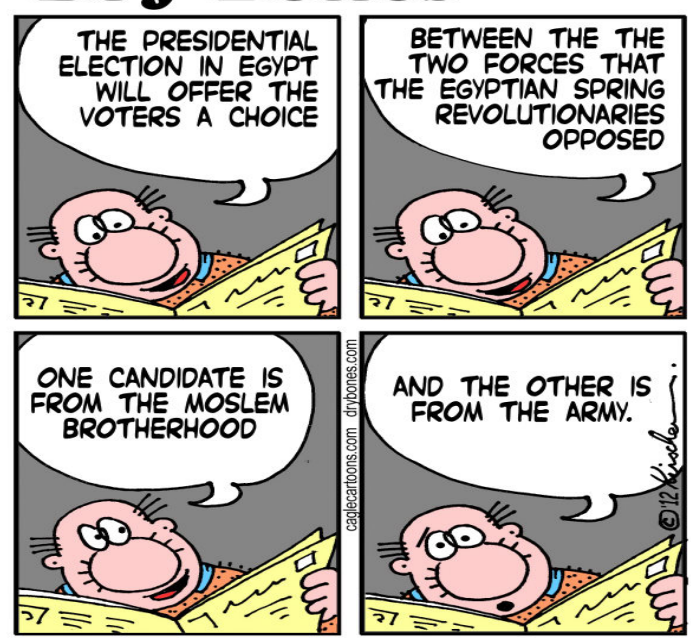

Figure 12. Cartoon 11: Dry Bones 4-8-2012.

Sholomo Cohen, the other Israeli cartoonist, also uses the verbal humor in his cartoon on the US-Egyptian relations. In this cartoon, the advisor of the U.S.. President Barack Obama standing behind him said: "Shave it back to place maybe they won't notice" while Obama tries to put back the stone of the Foreign Policy to prevent the temple of the Middle East from falling and breaking (see cartoon 12 in Figure 13).

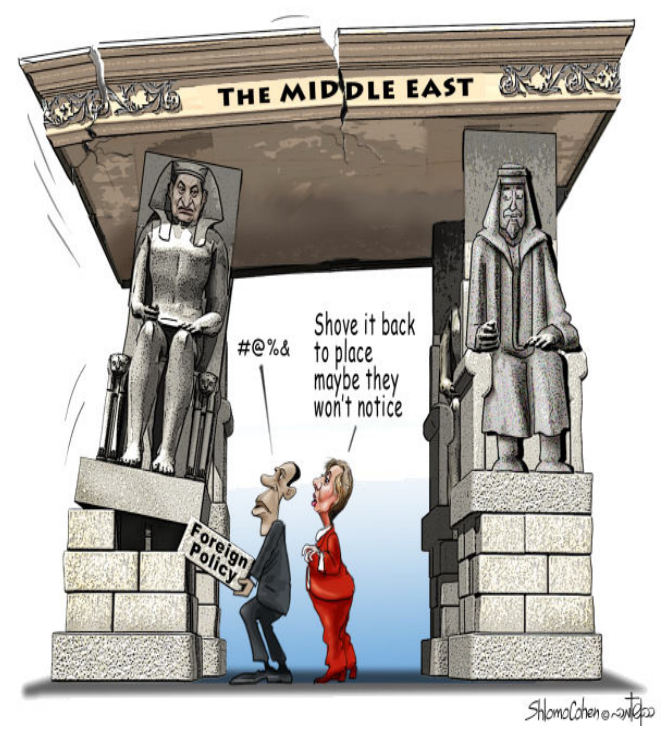

Figure 13. Cartoon 12: Shlomo Cohen 12-2-2011.

\section{RQ4: To What Extent Is Visual Analogy Applied in Analyzed Cartoons?}

Visual analogy is applied in this study on three levels: daily life, popular culture and historical references. 
Daily life. The Chinese Lujioe uses examples from daily life to clarify the meaning and transmit an obvious message to the reader. In cartoon 13 from Figure 14, he applies the domino and draws a cartoon on the dominos effect to clarify how the first hit caused by the statue of liberty caused the fall of all the dominos one after another which are Afghanistan, Iraq, Egypt, Libya and Syria.

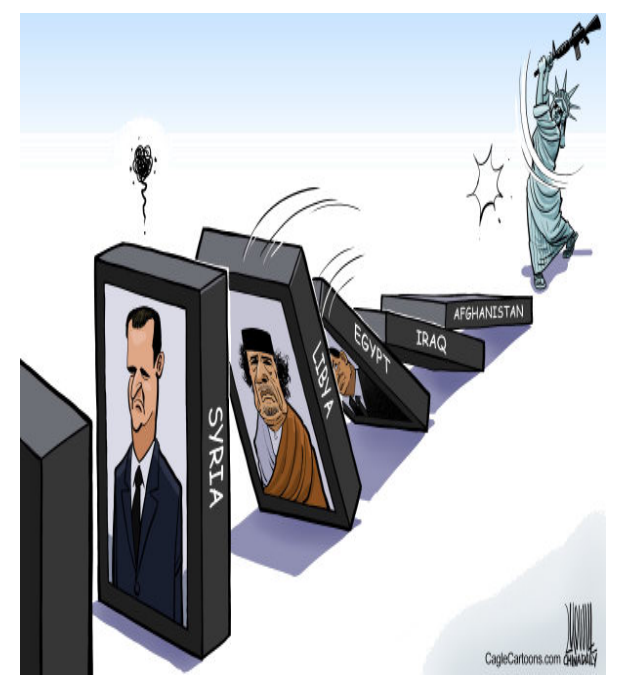

Figure 14. Cartoon 13: Lujioe 8-9-2011.

Popular culture. In cartoon 14 from Figure 15, Sergei Tunin depicts Egyptians riding a camel and wearing a jilbab which is the popular dress of men around Egypt. Here he chooses to focus more on the Arab perspective and the Arabic culture as he chooses to make the man wear that piece of cloth over his head.

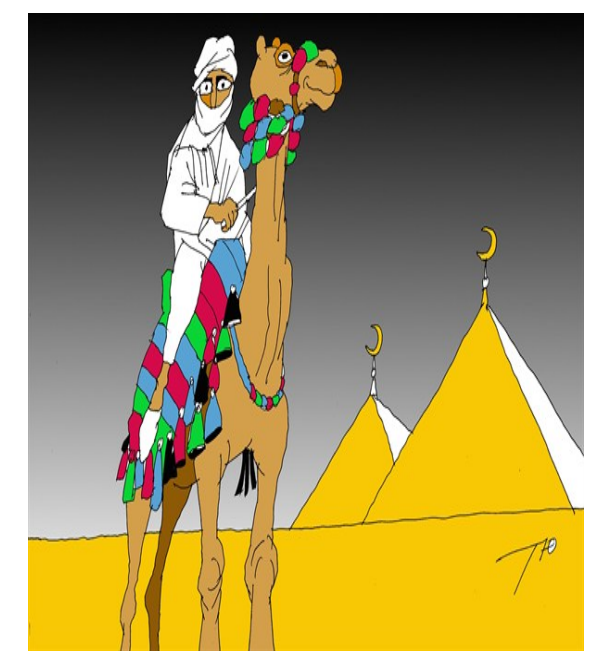

Figure 15. Cartoon 14: Sergei Tunin 28-5-2012.

Historical references. Lots of Asian cartoonists use historical references in depicting Egypt. Most of them use the pyramids, sphinx, the pharaohs and the clothes the pharaons were wearing. In cartoon 15 from Figure 16, the Russian Sergei Tunin chooses to draw the pyramid and the key of life one of the tools used in pharaonic Egypt to depict that the Egyptian revolution that happened in Egyptian dessert has drawn a new life to Egypt and that the Egyptians (the demonstrations) have drawn the key of life on Egypt's ground. 


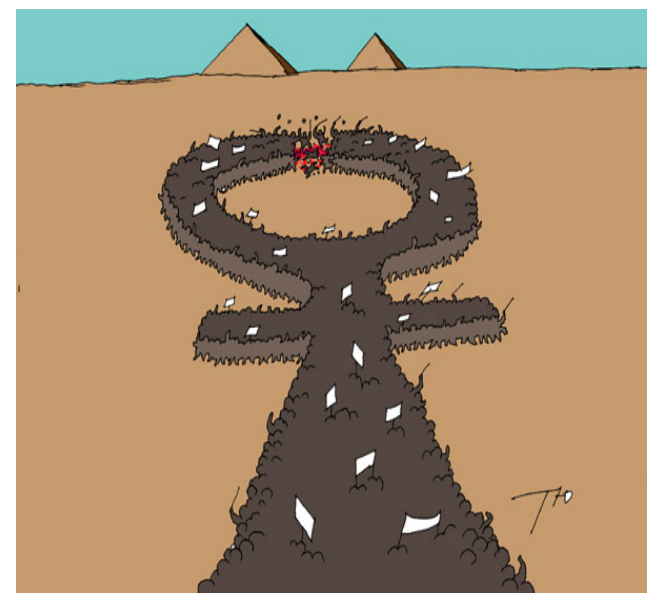

Figure 16. Cartoon 15: Sergei Tunin 7-2-2011.

\section{Conclusion}

This study concluded that Asian cartoons covered three main topics between 2011 and 2014: conflict between Mubarak and the people, conflict between Mursi and the people, and conflict between Mursi and the military. It also concluded that the people, Mursi and Egypt are the main actors covered by Asian cartoonists and applied several symbols. In this study, it is obvious that the Asian cartoonists used visual and verbal humor in order to convey their messages to the reader. Historical references are the main visual analogy in analyzed cartoons.

This study suggests future research in the field as research could be extended on African cartoons for more comparison while research could be conducted on any other Asian countries and cartoonists. This study also suggests that research could be applied with different tools of analysis such as critical discourse analysis CDA and framing analysis.

\section{References}

Abuelela, Y., \& El Maghraby, S. (2014). Framing political change in Egypt: How ideology influences coverage. Paper presented at the Annual Conference of the International Association for Media and Communication Research IAMCR, Hyderabad, India, July 2014.

El Maghraby, S. (2013). Cartoons and the Egyptian transition: A qualitative analysis of Egyptian newspapers. Global Media Journal, 4(1).

El Maghraby, S. (2013). Transition in Egypt as presented in cartoons: A semiological study on US Press. Arab Journal of Media \& Communication Research, second issue, July-September 2013. (in Arabic)

Guzman, A. L. (2012). US media frames of Egyptians revolution participants. Paper Presented at the Annual Meeting of the Association for Education in Journalism and Mass Communication, Chicago, I.L..

Osman, A., \& Abdel Samei, M. (2012). The media and the making of the 2011 Egyptian Revolution. Global Media Journal, 2(1).

Pennington, R. (2012). Stepping into modernity: Narratives of Egypt's January 25th uprising in New York Times Editorials. Paper presented at the Annual Meeting of the International Communication Association, Sheraton Phoenix Downtown, Phoenix, AZ, May 24, 2012 Online 2013-11-26. Available at:http://citation.allacademic.com/meta/p555893_index.html 